\title{
Cellular Physiology

\section{Upregulation of HERG Channels by the Serum and Glucocorticoid Inducible Kinase Isoform SGK3}

\author{
Gottlieb Maier, Monica Palmada, Jeyaganesh Rajamanickam, \\ Ekaterina Shumilina, Christoph Böhmer and Florian Lang
}

Department of Physiology, University of Tübingen

\author{
Key Words \\ HERG • Potassium channel $\cdot$ SGK $・$ Protein kinases \\ - Oocytes
}

\begin{abstract}
Human ether-a-go-go (HERG) channels participate in the repolarization of the cardiac action potential. Loss of function mutations of HERG lead to delayed cardiac repolarization reflected by prolonged QT interval. HERG channels are regulated through a signaling cascade involving phosphatidylinositol 3 (PI3) kinase. Downstream targets of PI3 kinase include the serum and glucocorticoid inducible kinase (SGK) and protein kinase $B(P K B)$ isoforms. The present study has been performed to explore whether SGK1 and SGK3 participate in the regulation of HERG channel activity. HERG was expressed in Xenopus oocytes with or without additional expression of SGK1 or SGK3. Chemiluminescence was employed to determine HERG plasma membrane protein abundance. Coexpression of SGK3 but not of SGK1 in Xenopus oocytes resulted in an increase of steady state current $\left(I_{\text {HERG }}\right)$ and enhanced cell membrane protein abundance without affecting gating kinetics
\end{abstract}

\section{KARGER}

Fax +4161306 1234

E-Mail karger@karger.ch

www.karger.com
(C) 2006 S. Karger AG, Basel

$1015-8987 / 06 / 0185-0177 \$ 23.50 / 0$

Accessible online at:

www.karger.com/journals/net of the channel. Replacement of serine by alanine at the two SGK consensus sites decreased I IERG but neither mutation abolished the stimulating effect of SGK3. In conclusion, SGK3 participates in the regulation of HERG by increasing HERG protein abundance in the plasma membrane and may thus modify the duration of the cardiac action potential.

Copyright (C 2006 S. Karger AG, Basel

\section{Introduction}

The serum and glucocorticoid inducible kinase (SGK1) has originally been cloned from rat mammary tumour cells as a glucocorticoid responsive gene [1-3]. Homology screening led to the discovery of the two isoforms SGK2 and SGK3 [4]. Similar to the related protein kinase B (PKB) all three SGK isoforms are activated by phosphorylation through a signaling cascade including phosphatidylinositol 3 (PI3) kinase and the 3phosphoinositide dependent kinases PDK1 and PDK2 [5-7]. The reported stimulators of SGK include insulin

Prof. Dr. Florian Lang

Physiologisches Institut, Universität Tübingen

Gmelinstr. 5, D-72076 Tübingen (Germany)

Tel. +49 7071/2972194, Fax +49 7071/295618

E-Mail florian.lang@uni-tuebingen.de 
$[6,8]$, insulin like growth factor IGF1 $[6,9]$, depolarization [10], cAMP [10] and oxidation [10].

SGK1 is under transcriptional control of glucocorticoids [11-15], mineralocorticoids [12, 16-22], as well as further hormones and mediators [23-25]. It is heavily expressed in fibrosing tissue [26-30]. SGK2 and SGK3 appear to be constitutively expressed and their transcription has hitherto not been shown to be sensitive to hormonal action [24]. Both, SGK1 [31] and SGK3 [4] are expressed in virtually all tissues tested including the heart. In vitro coexpression experiments disclosed the ability of SGK1 and/or SGK3 to activate the voltage-gated $\mathrm{Na}^{+}$channel SCN5A [32] and the $\mathrm{K}^{+}$channel KCNE1/ KCNQ1 [33]. The effect of the kinases on KCNE1/ KCNQ1 is expected to accelerate the repolarisation thus leading to shortening of the QT interval. As a matter of fact, the QT interval was found to be significantly shorter in carriers of a putative gain of function polymorphism of the SGK1 gene [34].

The effect of the kinases on SCN5A [32] and $\mathrm{KCNE} 1 / \mathrm{KCNQ} 1$ [33] is at least partially due to inhibition of the ubiquitin ligase Nedd4 or Nedd4-2. The ubiquitin ligase ubiquitinates target proteins thus preparing them for clearance from the cell membrane [35]. SGK1 phosphorylates Nedd4-2 and thus decreases the affinity of the ubiquitin ligase to its target proteins [36, 37].

Besides KCNE1/KCNQ1 the human ether-a-go-go (HERG) channel contributes to the repolarization of the cardiac action potential. Loss of function mutations of the genes encoding either KCNE1/KCNQ1 or HERG are known to delay cardiac repolarization and thus to cause long QT syndrome, a potentially lethal disorder of cardiac excitation $[38,39]$.

Recent evidence indicates that HERG channels are regulated by PI3 kinase [40]. Accordingly, pharmacological inhibition of PI3 kinase with Wortmannin decreased, whereas transfection of constitutively active PI3 kinase stimulated HERG activity. Transfection of constitutively active protein kinase $\mathrm{B}\left({ }^{\mathrm{T} 308 \mathrm{D}, 5473 \mathrm{D} P K B)}\right.$ mimicked the effect of PI3 kinase pointing to involvement of this kinase in the regulation of HERG channels [40]. The HERG sequence bears two putative phosphorylation sites for the serum and glucocorticoid inducible kinase isoforms SGK13 at position ${ }^{331}$ Ser and ${ }^{890}$ Ser.

The present study has been performed to explore whether the cardiac SGK isoforms SGK1 and SGK3 are capable to regulate HERG channels.

\section{Materials and Methods}

\section{Site directed mutagenesis of HERG}

The mutated HERG channels ${ }^{3331 \mathrm{~A}} \mathrm{HERG}$, ${ }^{\mathrm{S} 890 \mathrm{~A}} \mathrm{HERG}$ and S331AS890A HERG were generated by site-directed mutagenesis (QuikChange site-directed mutagenesis kit, Stratagene, Heidelberg, Germany) according to the manufacturer's instructions. The following primers were used:

S331AHERG,s: 5' CGC TAC CGC ACC ATT GCC AAG ATT CCC CAA ATC 3';

S331AHERG,as: 5' GAT TTG GGG AAT CTT GGC AAT GGT GCG GTA GCG 3';

S890AHERG,s: 5' CGC AAG CGC AAG TTG GCC TTC CGC AGG CGC ACG 3';

S890AHERG,as: 5' CGT GCG CCT GCG GAA GGC CAA CTT GCG CTT GCG 3'.

All mutants were sequenced to verify the presence of the desired mutation.

Expression in Xenopus oocytes and voltage-clamp analysis

cRNAs encoding wild type HERG, ${ }^{\mathrm{S} 331 \mathrm{~A}} \mathrm{HERG},{ }^{\mathrm{S} 890 \mathrm{~A}} \mathrm{HERG}$,

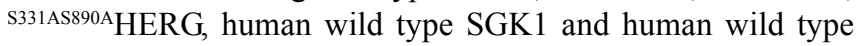
SGK3 were synthesized in vitro using a commercially available kit (Ambion, Austin, TX, USA) following the manufacturer's instructions.

Handling and injection of Xenopus oocytes and synthesis of cRNA have previously been described in detail [41]. Oocytes were first injected with water or $7.5 \mathrm{ng}$ cRNA encoding wild type SGK1 or SGK3 and one day later with 5ng cRNA encoding HERG. Standard two electrode voltage clamp recordings were performed 4 days after HERG injection. Oocytes were superfused continuously with ND-96 buffer containing (mM): $\mathrm{NaCl}$ 96, $\mathrm{KCl} 2, \mathrm{CaCl}_{2}$ 1.8, $\mathrm{MgCl}_{2} 1$ and HEPES 5 (pH 7.4 with $\mathrm{NaOH}$ ). Pipettes were filled with $3 \mathrm{M} \mathrm{KCl}$ and had resistances of 0.5-1.0 MW. Experiments were performed with a Geneclamp 500B amplifier (Axon Instruments, Union City, CA, USA) and a Digidata 1322A interface (Axon Instruments, Union City, CA, USA). Data acquisition was achieved with pCLAMP 9.0 (Axon Instruments, Union City, CA, USA). Activation curves were fitted with a Boltzmann distribution: $G(V)=G_{\max } /\left(1-\exp \left[\left(V_{1 / 2}-\right.\right.\right.$ $V) / k]$ ), where $V$ is the test pulse potential, $V_{1 / 2}$ is the half-maximal activation potential, and $k$ is the slope of the activation curve. All experiments were repeated with at least three batches of oocytes; in all repetitions, qualitatively similar data were obtained. HERG currents in the histograms were normalized by dividing the current of each oocyte by the mean current of the control group (HERG). For the kinetic analysis HERG currents were normalized by dividing the current of each oocyte at a given test voltage by the current evoked by the same oocyte at the most positive test voltage. Care was taken to use oocytes of the same developmental stage and diameter to minimize variation within the experimental groups. 
Fig. 1. SGK3 and PKB are potent stimulators of HERG activity. Xenopus oocytes were injected with wild type SGK1 or consti-

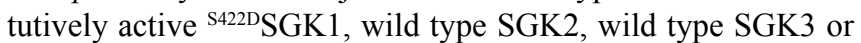
constitutively active ${ }^{\mathrm{T} 308 \mathrm{D} D, 5433 \mathrm{D}} \mathrm{PKB}$ and one day later with water or HERG cRNA. While neither SGK1 nor SGK2 affected HERG activity (A, B), both SGK3 and PKB stimulated HERG currents (B). No effects of protein kinases on background conductances could be detected (C). Four days after ion channel injection, HERG currents were quantified by two electrode voltage clamp. Arithmetic means \pm SEM. * indicates significant difference to cells injected with HERG alone. For analysis, $\mathrm{I}_{\text {HERG }}$ was taken after depolarizing the membrane potential to $0 \mathrm{mV}$ from $80 \mathrm{mV}$ holding potential. Arithmetic means \pm SEM.

Detection of cell surface expression by chemiluminescence

Chemiluminescence has widely been used for quantification of channel protein abundance at the cell surface [42]. Defolliculated oocytes were first injected with water or with human SGK3 cRNA (7.5 ng/oocyte), and one day later with extracellularly hemagglutinin (HA)-tagged HERG (7.5ng/ oocyte) [43]. Oocytes were incubated with $1 \mu \mathrm{g} / \mathrm{ml}$ primary rat monoclonal anti-HA antibody (clone 3F10, Boehringer, Germany) and $2 \mu \mathrm{g} / \mathrm{ml}$ secondary, peroxidase-conjugated affinitypurified $\mathrm{F}(\mathrm{ab}$ ') 2 goat anti-rat IgG antibody (Jackson ImmunoResearch, West Grove, USA). Individual oocytes were placed in $20 \mu \mathrm{l}$ of SuperSignal ELISA Femto Maximum Sensitivity Substrate (Pierce, Rockford, USA), and chemiluminescence was quantified in a luminometer by integrating the signal over a period of 1s. The SuperSignal ELISA Femto Maximum Sensitivity Substrate contains Luminol as the substrate of the chemiluminescence reaction. The emitted light output is linearly dependent on the amount of peroxidase conjugated to the $2^{\text {nd }}$ antibody. Integrity of the measured oocytes was assessed by visual control after the measurement to avoid unspecific light signals from the cytosol. As a control, background luminescence was measured from non-injected oocytes.

\section{Western blotting}

For determination of HERG expression in whole cell lysates, oocytes were homogenized in lysis buffer containing $50 \mathrm{mM}$ Tris (pH 7.5), $0.5 \mathrm{mM}$ EDTA (pH 8.0), $0.5 \mathrm{mM}$ EGTA, $100 \mathrm{mM} \mathrm{NaCl}, 1 \%$ Triton X-100 and protease inhibitor cocktail (Roche, Penzberg, Germany) at the recommended concentrations. $30 \mu \mathrm{g}$ of total protein were separated in a $10 \%$ polyacrylamide gel and transferred to a nitrocellulose membrane at $100 \mathrm{~V}$ for $90 \mathrm{~min}$. For immunoblotting, rabbit anti-HERG antibody (Alomone Labs, Jerusalem, Israel, diluted 1:400 in PBS $/ 0.15 \%$ Tween $20 / 5 \%$ nonfat dry milk) was used to detect HERG protein. After blocking with 5\% nonfat dry milk in PBS/ $0.15 \%$ Tween 20 for $1 \mathrm{~h}$ at room temperature, blots were incubated with the primary antibody for an additional hour at room temperature. Secondary peroxidase-conjugated sheep anti-rabbit IgG (Amersham, Freiburg, Germany, diluted 1:1000 in PBS/0.15\% Tween 20/5\% nonfat dry milk) were incubated overnight at $4^{\circ} \mathrm{C}$ and used for luminescent detection with an

SGK and HERG Channel
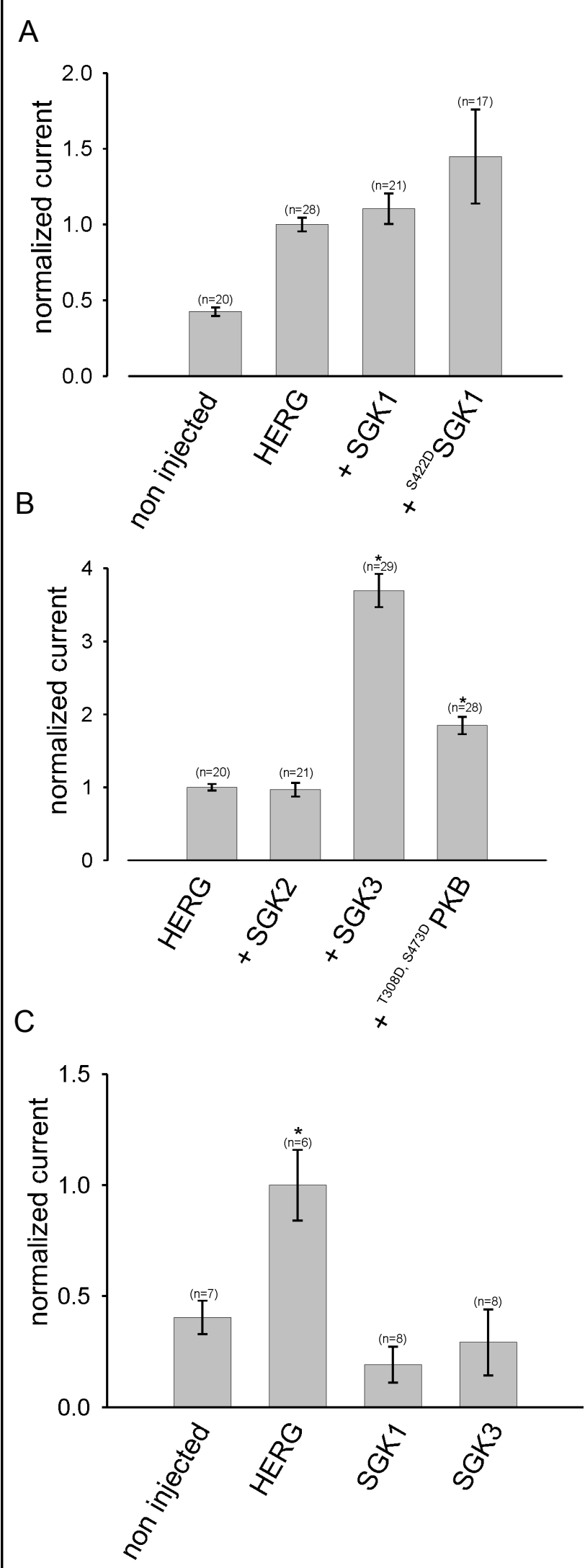

Cell Physiol Biochem 2006;18:177-186 


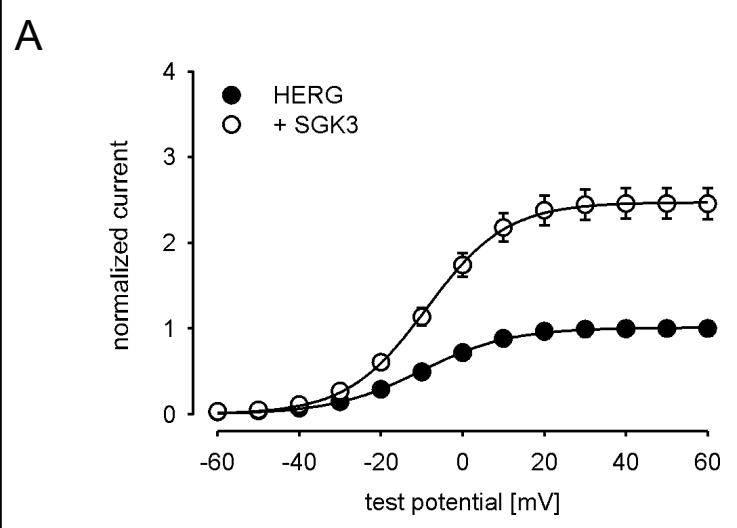

D

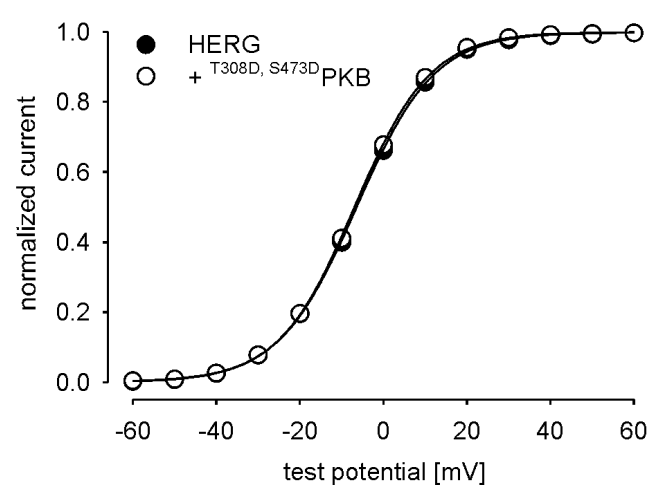

B

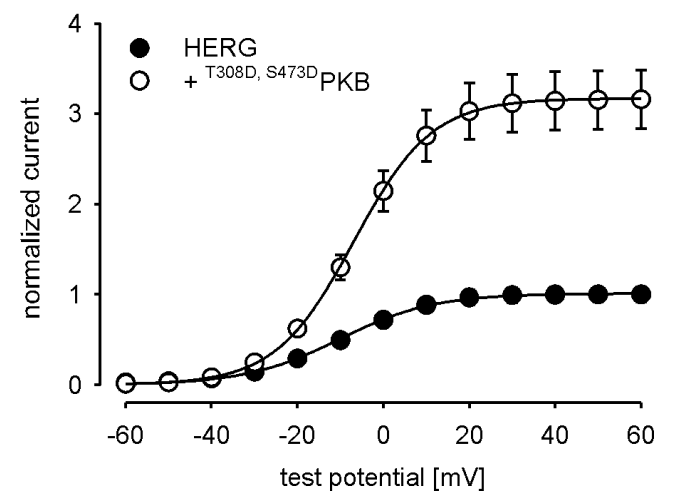

$E$
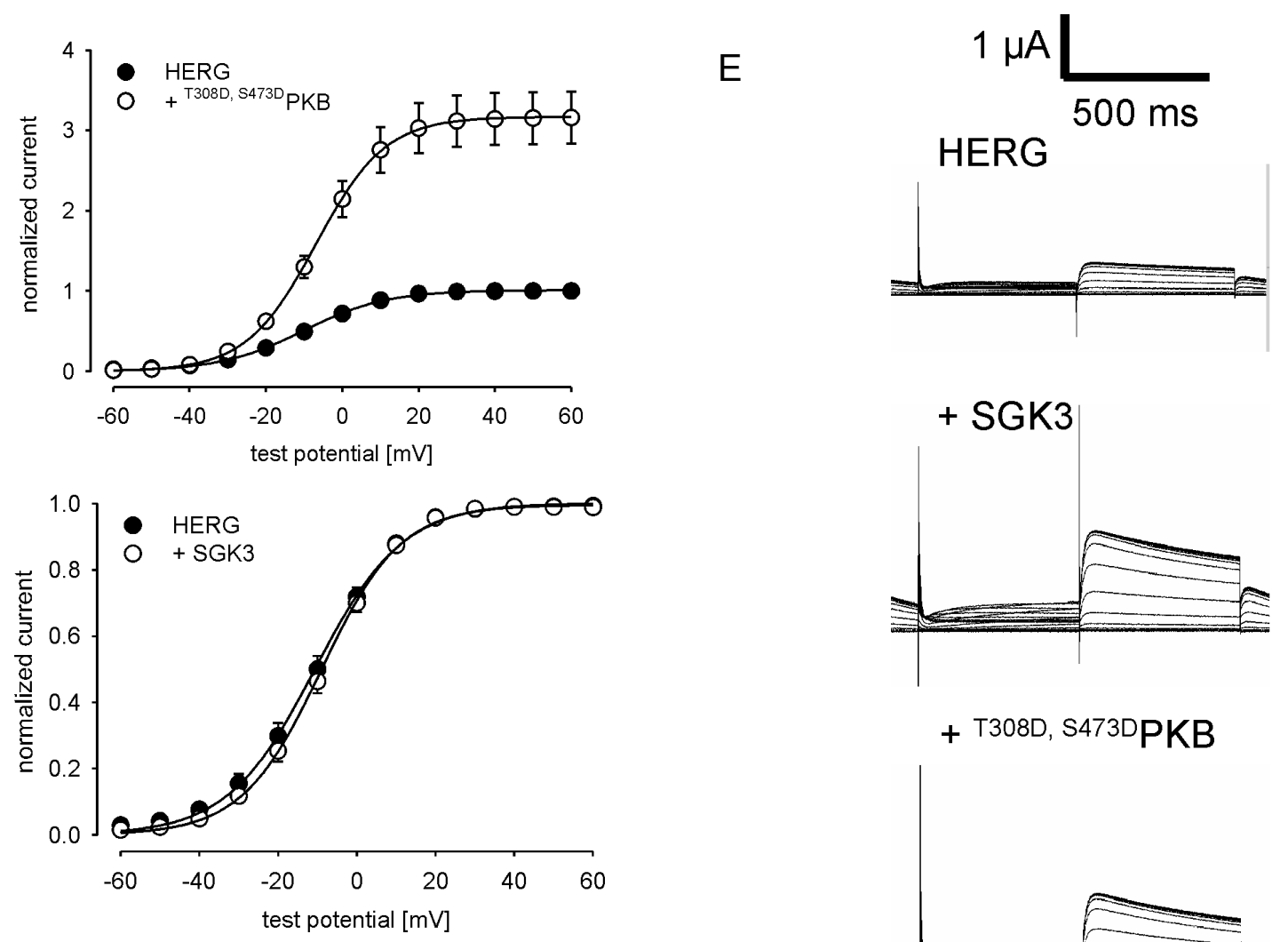

+ T308D, S473DPKB

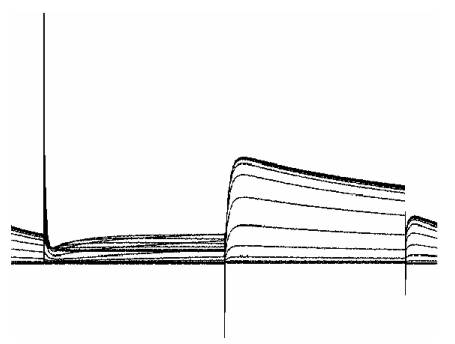

$\mathrm{F}$

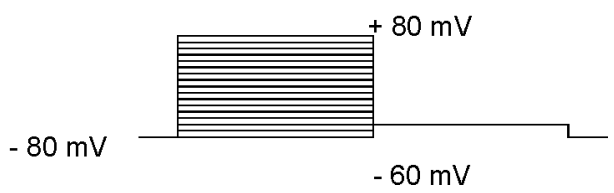

Fig. 2. HERG channel kinetics in the absence and presence of SGK3 or PKB. HERG gating kinetics remained unaffected upon

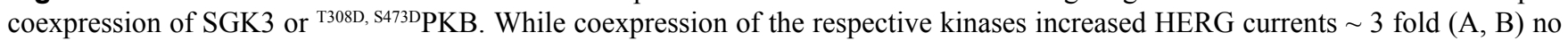
change in gating behaviour of the channel could be observed $(C, D)$. Peak tail currents were normalized to the maximum current amplitude in cells expressing HERG in A and B. In C and D currents were normalized to the maximum peak tail current in the same group. Arithmetic means \pm SEM. (E) Typical original recordings. $\mathrm{N}=6-14$. (F) Voltage protocol applied for the recordings depicted in E. 
enhanced chemoluminescence (ECL) kit (Amersham, Freiburg, Germany).

Data and statistical analysis

Experimental data are expressed as arithmetic means \pm SEM. Statistical significance was tested by using ANOVA, $\mathrm{P}<$ 0.05 was considered statistically significant.

\section{Results}

Heterologous expression of HERG channels in Xenopus laevis oocytes led to the induction of a voltage gated current. Coexpression of the constitutively active serum and glucocorticoid inducible kinase isoform 1 ( ${ }^{\text {S422D }}$ SGK1) or the wild type SGK1 did not significantly alter $\mathrm{I}_{\mathrm{HERG}}$ (Fig. 1A). In contrast, the wild type SGK3 strongly activated $\mathrm{I}_{\mathrm{HERG}}$. As depicted in Fig. 1B, coexpression of SGK3 or constitutively active T308D,S473DPKB, used in this experiment as positive control, increased HERG activity almost fourfold. In contrast, SGK2 did not enhance $I_{\text {HERG }}$. The SGK kinases did not have any effect on intrinsic voltage activated conductances (Fig. 1C).

Conformational changes of voltage activated channels due to phosphorylation may affect the gating kinetics of the protein. To characterize HERG gating, test potentials ranging from $-60 \mathrm{mV}$ to $+60 \mathrm{mV}$ were applied to trigger activating currents. The test pulses were followed by a $400 \mathrm{~ms}$ pulse to $-60 \mathrm{mV}$ to evoke outward tail currents. Fig. 2 summarizes the current voltage relationship of HERG currents upon coexpression of SGK3 or PKB. The amplitude of the peak tail current was plotted as a function of the preceding test potential. The left panel (A, B) displays the absolute current values to demonstrate potent upregulation of the current by SGK3 and PKB. The right panel (C, D) depicts peak tail currents that were normalized to the maximum peak tail current of the respective group to investigate kinetics. As obvious from $\mathrm{C}$ and $\mathrm{D}$, coexpression of neither SGK3 nor PKB led to a shift of the voltage required for half maximal peak tail currents.

The HERG protein contains two putative SGK phosphorylation sites on its sequence at ${ }^{331}$ Ser and ${ }^{890}$ Ser. We generated the three mutations ${ }^{\mathrm{S} 331 \mathrm{~A}} \mathrm{HERG}$,

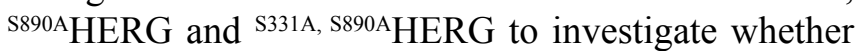
PKB and SGK3 modulate HERG by phosphorylating the channel directly. Replacement of serine by alanine in the first phosphorylation site in ${ }^{\mathrm{S3} 31 \mathrm{~A}} \mathrm{HERG}$ decreased $\mathrm{I}_{\text {HERG }}$ by some $64 \%$ (Fig. 3). The activity of ${ }^{8890 A}$ HERG was only some $14 \%$ of the current mediated by the wild type

SGK and HERG Channel

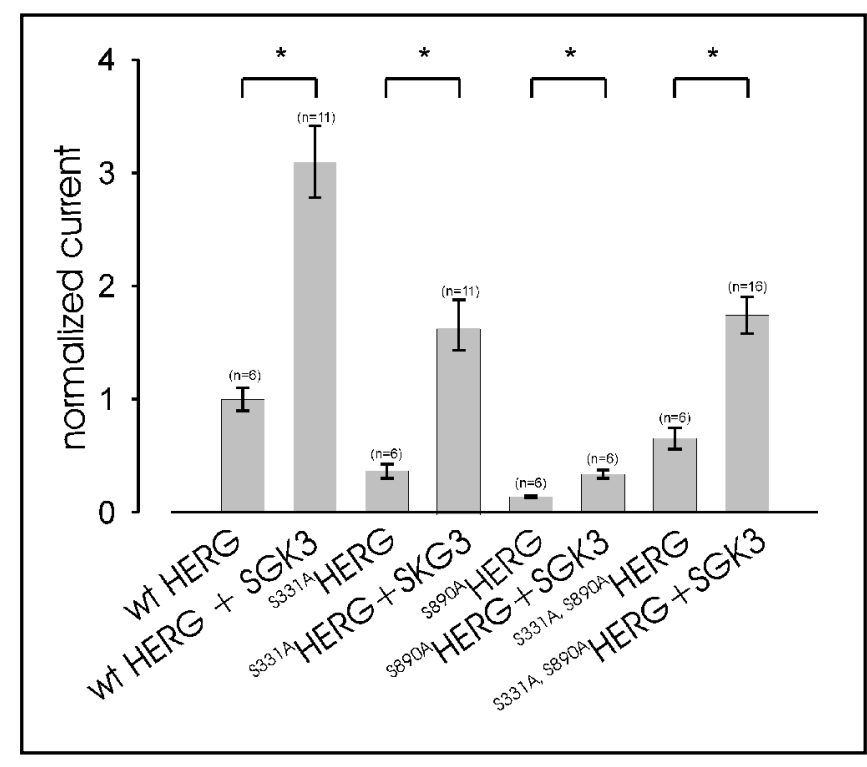

Fig. 3. Destruction of the putative SGK phosphorylation sites on the HERG protein does not prevent channel upregulation by SGK3. Comparable to the effect on wtHERG, SGK3 stimulated current activity of the ${ }^{\mathrm{S} 331 \mathrm{~A}} \mathrm{HERG},{ }^{\mathrm{S} 890 \mathrm{~A}} \mathrm{HERG}$ and ${ }^{\mathrm{S} 331 \mathrm{~A}}$, ${ }^{\mathrm{S} 890 \mathrm{~A}} \mathrm{HERG} \sim 3$ fold. Currents evoked by the respective mutant HERG constructs were significantly lower compared to the wild type channel (Clamp protocol as in Fig. 1). Arithmetic means \pm SEM.

channel. Mutation of both phosphorylation sites on the S331A, S890A HERG decreased the currents to $65 \%$ of the current mediated by the wild type channel (Fig. 3). Destruction of the putative phosphorylation sites did not prevent channel activation by SGK3. SGK3 coexpression did not only increase the current carried by wild type HERG (by 209\%) but similarly increased the current carried by the ${ }^{\mathrm{S} 331 \mathrm{~A}, \mathrm{~S} \text { S80A }}{ }^{\mathrm{A}} \mathrm{HERG}$ double mutant $(166 \%)$, the ${ }^{\mathrm{S} 331 \mathrm{~A}} \mathrm{HERG}$ mutant (by 354\%) and the ${ }^{\mathrm{S} 890 \mathrm{~A}} \mathrm{HERG}$ mutant (by 143\%).

As depicted in Fig. 4, destruction of the putative phosphorylation sites did not change HERG activation kinetics. Channel activation was neither affected in the HERG double nor single mutants. Also, channel kinetics were unaffected by coexpression of the SGK3 protein kinase. The upper panel (A) depicts current values normalized to the maximum peak tail currents of cells expressing HERG without SGK3. In panel B current values were plotted normalized to the maximum peak tail currents of the same group. Thus, activation of HERG currents by SGK3 is not due to a change in activation kinetics.

Cell Physiol Biochem 2006;18:177-186 

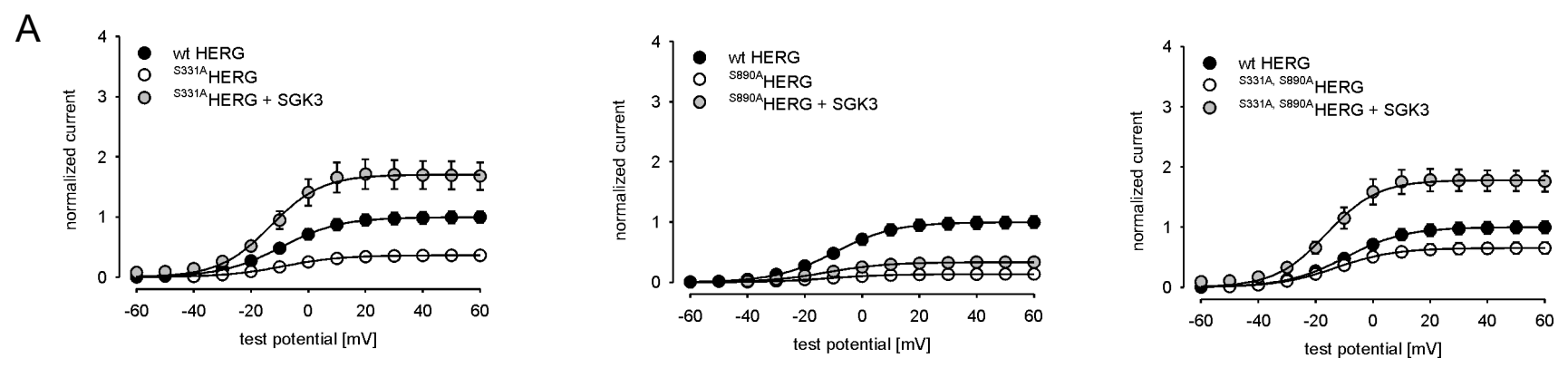

B
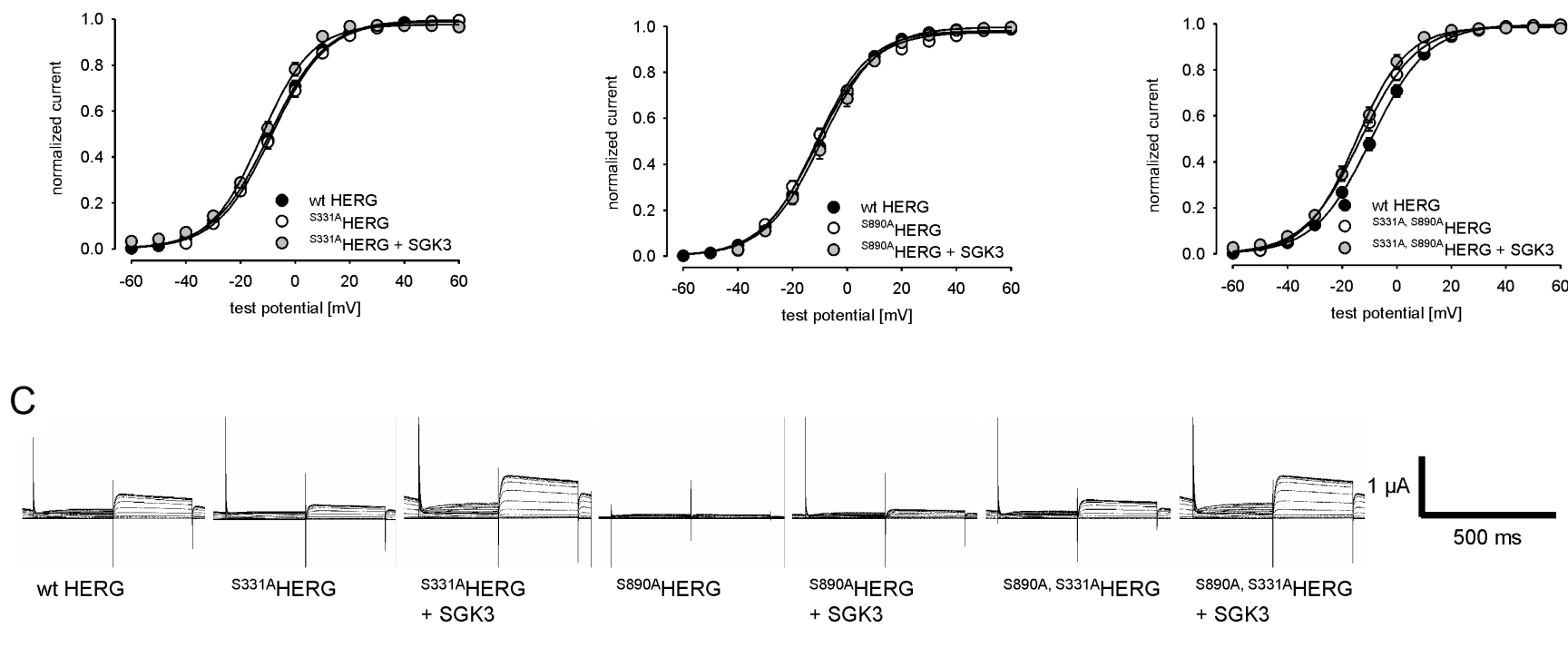

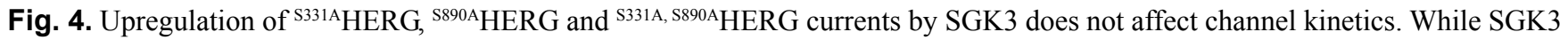
induced HERG currents evoked by the SGK phosphorylation site mutants ${ }^{\mathrm{S} 331 \mathrm{~A} H E R G,}{ }^{\mathrm{S} 890 \mathrm{~A}} \mathrm{HERG}$ and ${ }^{\mathrm{S} 331 \mathrm{~A}, \mathrm{~S} 890 \mathrm{~A}} \mathrm{HERG}(\mathrm{A})$, the channel kinetics remained unaffected (B). The slight shift of the curve observed with the double mutated ${ }^{\mathrm{S} 331 \mathrm{~A}, \mathrm{~S} 890 \mathrm{~A} H E R G}$ was not significantly different compared to control (Clamp protocol as in Fig. 1). Arithmetic means \pm SEM. $n=8-15$. (C) Typical original recordings.

Although HERG tail currents and activation kinetics are of major physiological importance, HERG phosphorylation may also affect steady state deactivation of the channel in the Xenopus oocyte expression system. Deactivation kinetics are summarized in Fig. 5. Coexpression of SGK3 did not affect the deactivation time constant $\tau$ (A) while absolute HERG currents were significantly activated by the SGK protein kinase (B).

To quantify HERG protein cell surface abundance, we generated a hemagluttinin tagged HERG construct. Proper expression of this HA-tagged HERG was demonstrated by Western blotting of whole cell lysates
(Fig. 6A). HERG/GAPDH band intensity quantification indicated that total HERG protein abundance was not significantly affected by SGK3. Coexpression of SGK3 led to an enhancement of HERG plasma membrane expression by $151 \%$ as monitored by chemiluminescence of extracellularly HA-tagged HERG proteins (B). As demonstrated by electrophysiology, the insertion of the HA tag did not affect channel function. The coexpression of SGK3 increased the HERG(HA) induced current significantly (C). Similar to what has already been shown for the wild type channel, HERG(HA) kinetics were not affected by SGK3 (D).

Maier/Palmada/Rajamanickam/Shumilina/Böhmer/Lang 


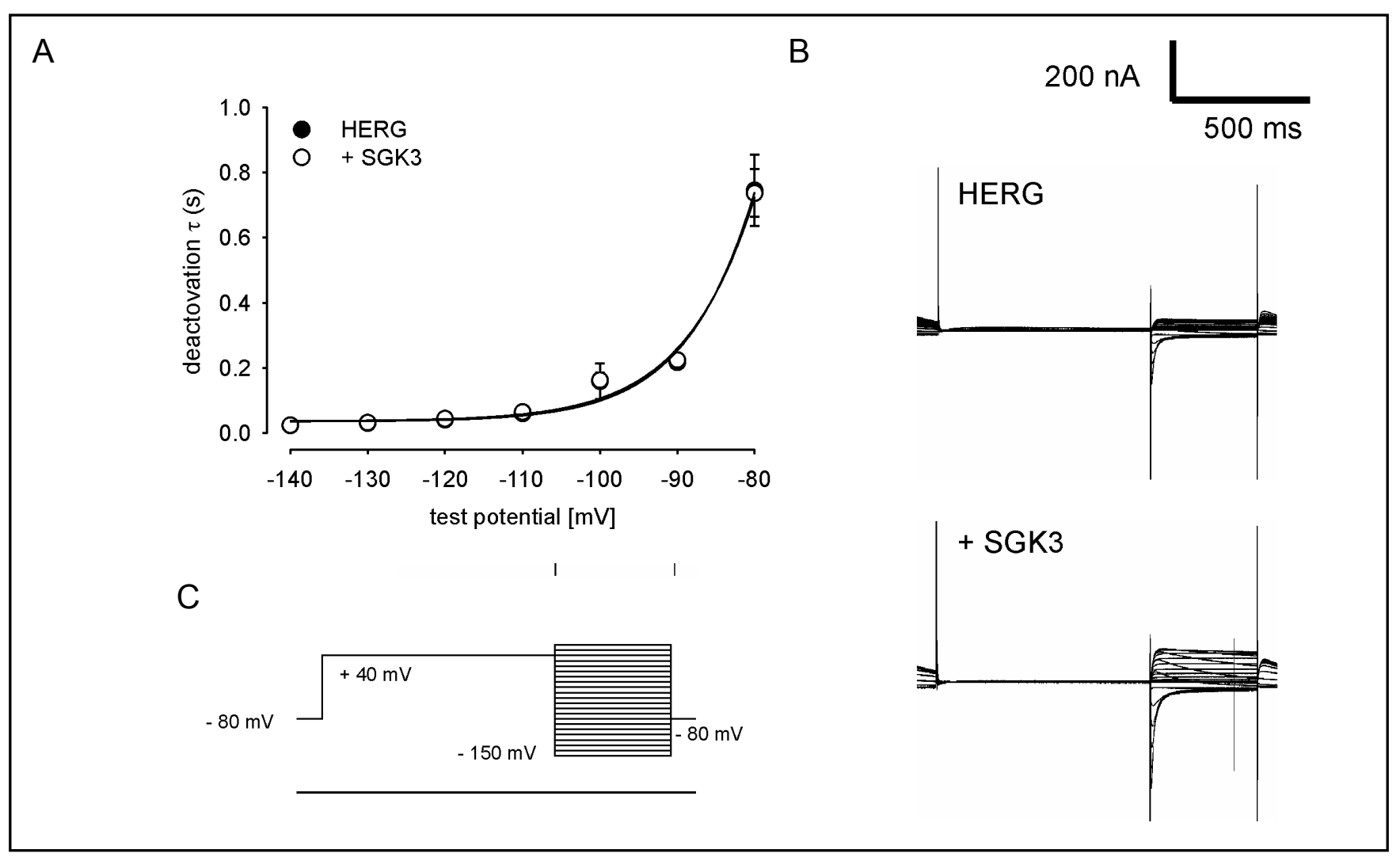

Fig 5. HERG channel deactivation kinetics in the absence and presence of SGK3. HERG deactivation kinetics remained unaffected upon coexpression of SGK3 (A) while SGK3 absolute currents were increased upon coexpression of the kinase as depicted in the original recordings in B. (C) Voltage protocol applied for the recordings shown in B. $\mathrm{n}=8-11$.

\section{Discussion}

The present results demonstrate that the serine and threonine kinase SGK3 upregulates HERG channel currents by enhancing the channel abundance in the plasma membrane whereas it has no effect on intrinsic conductances of the Xenopus laevis oocyte. The unchanged total amount of HERG protein indicates that the observed increase of channel cell surface abundance is due to posttranslational rather than translational regulation. This observation casts new light on the functional significance of SGK3. The kinase has previously been shown to upregulate KCNE1/KCNQ1 [33], the other key potassium channel involved in cardiac repolarization [39]. Thus, SGK3 is an excellent candidate signalling molecule in the regulation of cardiac repolarization.

SGK1 failed to regulate HERG channels. This finding may be considered surprising, given that a certain variant of the SGK1 gene is associated with a decrease of the QT interval [34]. The influence of SGK1 on the QT

SGK and HERG Channel interval is probably the result of its effect on KCNE1/ KCNQ1 [33]. As SGK3 stimulates both KCNE1/KCNQ1 [33] and HERG, its influence on cardiac repolarization may be even more potent than that of SGK1. However, the present in vitro results cannot be translated into the in vivo situation without reservations and presently no polymorphisms of SGK3 are known which could be correlated with the QT interval. In any case, all three kinases, SGK1 [31], SGK3 [4] and PKB [40] are expressed in cardiac tissue and all three kinases could participate in the regulation of cardiac ion channels. Their relative activity and thus their potential impact on ion channels, however, remain uncertain. Moreover, the relative contribution may depend on the functional condition. SGK3 appears to be constitutively expressed and less sensitive to transcriptional regulation [24]. In contrast SGK1 is under strong transcriptional control of cell volume [44, 45], glucocorticoids [1-3], or mineralocorticoids [12, 16-18, 20, 21]. Thus, SGK1 may allow adaptation to certain physiological and pathophysiological challenges whereas the 
A

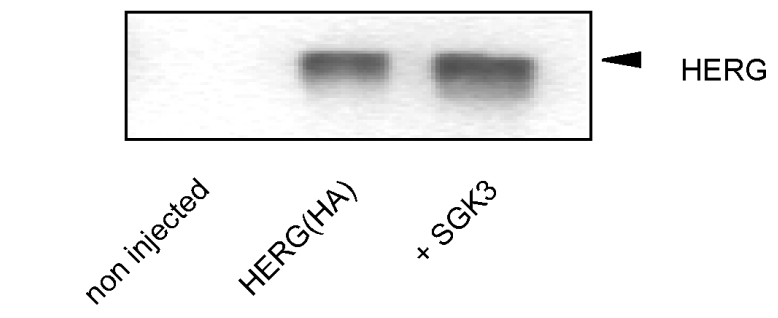

C

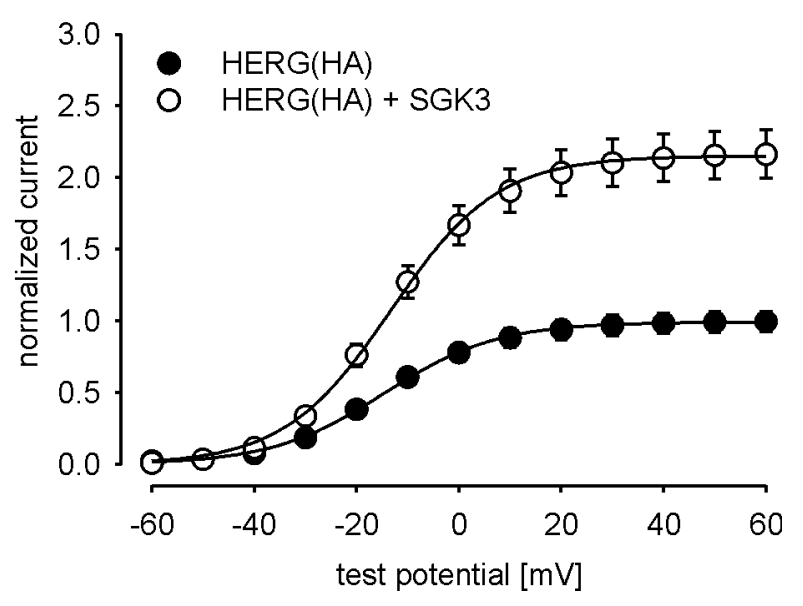

B
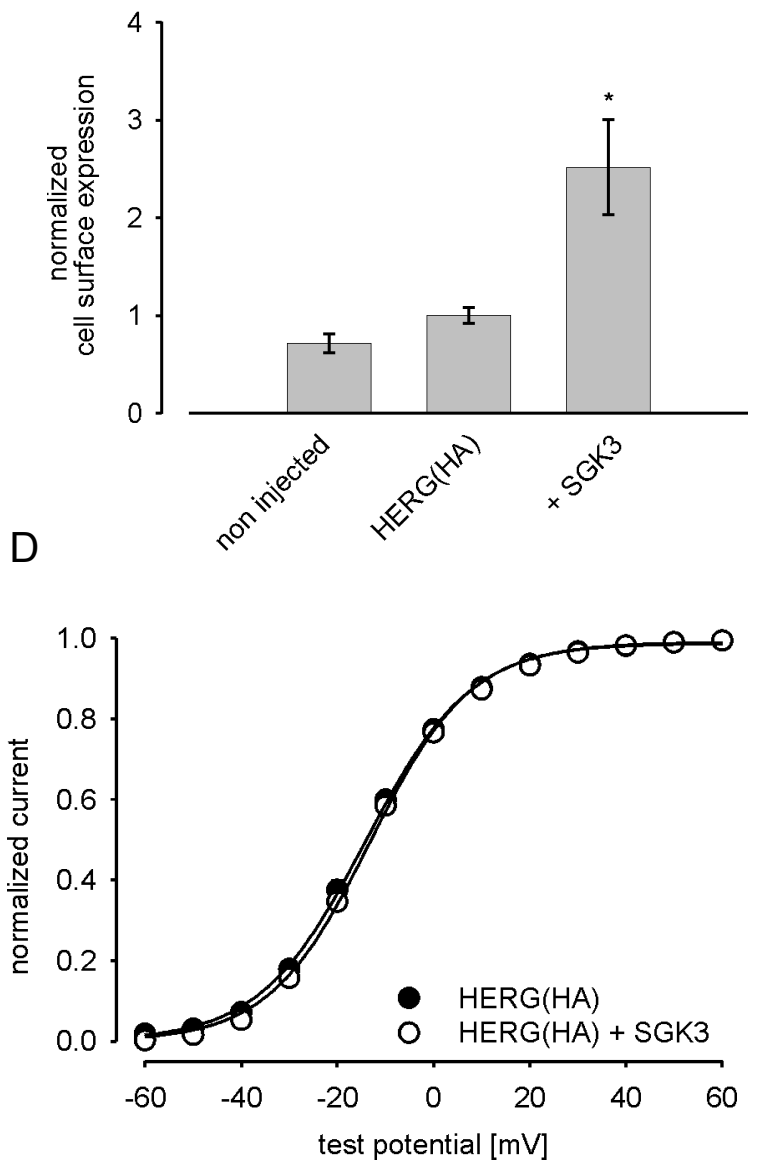

Fig. 6. Current amplitudes and plasma membrane abundance of HA-tagged HERG channels upon coexpression of SGK3. Xenopus oocytes were injected with water or SGK3 cRNA and one day later with HA-tagged HERG cRNA. Western blotting of whole cell lysates was performed to verify proper HERG expression $(A), n=3$. Four days after HERG injection, plasma membrane abundance $(B)$ and HERG mediated currents $(C, D)$ were measured $(n=8-14)$. Arithmetic means \pm SEM, * indicates significant difference to cells injected with HERG alone. Enhanced channel activity upon SGK3 coexpression correlated with enhanced channel abundance in the plasma membrane. A representative Western blot is shown demonstrating HERG and SGK3 expression.

regulation by SGK3 may be less variable.

The present observations suggest that SGK3 is not effective through direct phosphorylation of the HERG channel. The replacement of the serines by alanines in the SGK consensus sequences affects HERG channel activity but does not abrogate the stimulating effect of the kinase. Furthermore, the co-immunoprecipitation experiments suggest that the kinase does not bind to the HERG channel directly. In previous reports from our laboratory we demonstrated that SGK may regulate some cell membrane transporters and ion channels through direct phosphorylation of the membrane protein [46] or through indirect modulation via the ubiquitin ligase Nedd42 [36, 47, 48]. SGK phosphorylates Nedd4-2 thus decreasing its substrate affinity and preventing ubiquitination and degradation of the transporter or ion channel [36]. Both mechanisms may occur in parallel. Compelling evidence suggests, however, the involvement of further mechanisms in addition to direct phosphorylation of the respective transport system and in addition to Nedd4-2 [49, 50]. Like these transporters, HERG channel activity and expression is not affected by Nedd4-2 (own observation) and similarly seems not to be directly targeted by SGK phosphorylation. Thus, the kinase may

Maier/Palmada/Rajamanickam/Shumilina/Böhmer/Lang 
be effective through phosphorylation of a hitherto unknown intermediate protein.

In conclusion, SGK3 modulates the cardiac HERG channel activity by enhancing HERG abundance in the plasma membrane without affecting HERG activation kinetics. Thus the kinase may participate in the regulation of cardiac repolarization under physiological and pathophysiological conditions.

\section{Acknowledgements}

The authors acknowledge Dr. Sanguinetti (University of Utah, UT, USA) for the gift of HA-tagged HERG. F.L. was supported by grants-in-aid from the Deutsche Forschungsgemeinschaft and M.P. by a Marie Curie Grant (QLGA-CT-2001-52014), E. Shumilina by a grant from the Alexander von Humboldt foundation.

\section{References}

Firestone GL, Giampaolo JR, O'Keeffe BA: Stimulus-dependent regulation of the serum and glucocorticoid inducible protein kinase (Sgk) transcription, subcellular localization and enzymatic activity. Cell Physiol Biochem 2003;13:1-12.

2 Webster MK, Goya L, Firestone GL: Immediate-early transcriptional regulation and rapid mRNA turnover of a putative serine/threonine protein kinase. J Biol Chem 1993;268:11482-11485.

Webster MK, Goya L, Ge Y, Maiyar AC, Firestone GL: Characterization of sgk, a novel member of the serine/threonine protein kinase gene family which is transcriptionally induced by glucocorticoids and serum. Mol Cell Biol 1993;13:2031-2040.

-4 Kobayashi T, Deak M, Morrice N, Cohen $\mathrm{P}$ : Characterization of the structure and regulation of two novel isoforms of serum- and glucocorticoid-induced protein kinase. Biochem J 1999;344:189-197. Biondi RM, Kieloch A, Currie RA, Deak M, Alessi DR: The PIF-binding pocket in PDK1 is essential for activation of S6K and SGK, but not PKB. EMBO J 2001;20:4380-4390.

-6 Kobayashi T, Cohen P: Activation of serum- and glucocorticoid-regulated protein kinase by agonists that activate phosphatidylinositide 3-kinase is mediated by 3-phosphoinositide-dependent protein kinase-1 (PDK1) and PDK2. Biochem J 1999;339:319-328.
Park J, Leong ML, Buse P, Maiyar AC, Firestone GL, Hemmings BA: Serum and glucocorticoid-inducible kinase (SGK) is a target of the PI 3-kinase-stimulated signaling pathway. EMBO J 1999;18:3024-3033.

Perrotti N, He RA, Phillips SA, Haft CR, Taylor SI: Activation of serum- and glucocorticoid-induced protein kinase (Sgk) by cyclic AMP and insulin. J Biol Chem 2001;276:9406-9412.

Hayashi M, Tapping RI, Chao TH, Lo JF, King CC, Yang Y, Lee JD: BMK1 mediates growth factor-induced cell proliferation through direct cellular activation of serum and glucocorticoid-inducible kinase. J Biol Chem 2001;276:86318634.

-10 Kumari S, Liu X, Nguyen T, Zhang X, D'Mello SR: Distinct phosphorylation patterns underlie Akt activation by different survival factors in neurons. Brain Res Mol Brain Res 2001;96:157-162.

Boulkroun S, Fay M, Zennaro MC, Escoubet B, Jaisser F, Blot-Chabaud M, Farman N, Courtois-Coutry N: Characterization of rat NDRG2 (N-Myc downstream regulated gene 2), a novel early mineralocorticoid-specific induced gene. J Biol Chem 2002;277:31506-31515. Brennan FE, Fuller PJ: Rapid upregulation of serum and glucocorticoid-regulated kinase (sgk) gene expression by corticosteroids in vivo. Mol Cell Endocrinol 2000;166:129-136.
Cooper MS, Bujalska I, Rabbitt E, Walker EA, Bland R, Sheppard MC, Hewison M, Stewart PM: Modulation of 11 betahydroxysteroid dehydrogenase isozymes by proinflammatory cytokines in osteoblasts: an autocrine switch from glucocorticoid inactivation to activation. $\mathrm{J}$ Bone Miner Res 2001;16:1037-1044.

Mikosz CA, Brickley DR, Sharkey MS, Moran TW, Conzen SD: Glucocorticoid receptor-mediated protection from apoptosis is associated with induction of the serine/threonine survival kinase gene, sgk-1. J Biol Chem 2001;276:16649-16654.

15 Naray-Fejes-Toth A, Fejes-Toth G, Volk KA, Stokes JB: SGK is a primary glucocorticoid-induced gene in the human. J Steroid Biochem Mol Biol 2000;75:5156.

Bhargava A, Fullerton MJ, Myles K, Purdy TM, Funder JW, Pearce D, Cole TJ: The serum- and glucocorticoid-induced kinase is a physiological mediator of aldosterone action. Endocrinology 2001;142:1587-1594.

17 Chen SY, Bhargava A, Mastroberardino L, Meijer OC, Wang J, Buse P, Firestone GL, Verrey F, Pearce D: Epithelial sodium channel regulated by aldosteroneinduced protein sgk. Proc Natl Acad Sci U S A 1999;96:2514-2519.

Loffing J, Zecevic M, Feraille E, Kaissling B, Asher C, Rossier BC, Firestone GL, Pearce D, Verrey F: Aldosterone induces rapid apical translocation of $\mathrm{ENaC}$ in early portion of renal collecting system: possible role of SGK. Am J Physiol Renal Physiol 2001;280:F675-F682. 
19 Naray-Fejes-Toth A, Canessa C, 30 Cleaveland ES, Aldrich G, Fejes-Toth G: Sgk is an aldosterone-induced kinase in the renal collecting duct. Effects on epithelial $\mathrm{Na}+$ channels. J Biol Chem 1999;274:16973-16978.

Pearce D: SGK1 Regulation of Epithelial Sodium Transport. Cell Physiol Biochem 2003;13:013-020.

-21 Shigaev A, Asher C, Latter H, Garty H, Reuveny E: Regulation of sgk by aldosterone and its effects on the epithelial $\mathrm{Na}(+)$ channel. Am J Physiol Renal Physiol 2000;278:F613-F619.

-22 Verrey F, Loffing J, Zecevic M, 32 Heitzmann D, Staub O: SGK1: aldosterone-induced relay of $\mathrm{Na}+$ transport regulation in distal kidney nephron cells. Cell Physiol Biochem 2003;13:021-028.

$>23$ Cowling RT, Birnboim HC: Expression of serum- and glucocorticoid-regulated kinase (sgk) mRNA is up-regulated by GM-CSF and other proinflammatory mediators in human granulocytes. J Leukoc Biol 2000;67:240-248.

24 Lang F, Cohen P: Regulation and physiological roles of serum- and glucocorticoid-induced protein kinase isoforms. Sci STKE 2001;2001:RE17.

25 Vereninov AA, Vassilieva IO, Yurinskaya VE, Matveev VV, Glushankova LN, Lang F, Matskevitch JA: Differential transcription of ion transporters, NHE1, ATP1B1, NKCC1 in human peripheral blood lymphocytes activated to proliferation. Cell Physiol Biochem 2001;11:19-26.

-26 Fillon S, Klingel K, Warntges S, Sauter M, Gabrysch S, Pestel S, Tanneur V, Waldegger S, Zipfel A, Viebahn R, Haussinger D, Broer S, Kandolf R, Lang F: Expression of the serine/threonine kinase hSGK1 in chronic viral hepatitis. Cell Physiol Biochem 2002;12:47-54.

$>27$ Klingel K, Warntges S, Bock J, Wagner CA, Sauter M, Waldegger S, Kandolf R, Lang F: Expression of cell volume-regulated kinase h-sgk in pancreatic tissue. Am J Physiol Gastrointest Liver Physiol 2000;279:G998-G1002.

$>28$ Lang F, Klingel K, Wagner CA, Stegen C, Warntges S, Friedrich B, Lanzendorfer M, Melzig J, Moschen I, Steuer S, Waldegger S, Sauter M, Paulmichl M, Gerke V, Risler T, Gamba G, Capasso G, Kandolf R, Hebert SC, Massry SG, Broer $\mathrm{S}$ : Deranged transcriptional regulation of cell-volume-sensitive kinase hSGK in diabetic nephropathy. Proc Natl Acad Sci U S A 2000;97:8157-8162.

Waldegger S, Klingel K, Barth P, Sauter $>40$ M, Rfer ML, Kandolf R, Lang F: h-sgk serine-threonine protein kinase gene as transcriptional target of transforming growth factor beta in human intestine. Gastroenterology 1999;116:1081-1088.
Wärntges S, Klingel K, Weigert C, Fillon S, Buck M, Schleicher E, Rodemann HP, Knabbe C, Kandolf R, Lang F: Excessive transcription of the human serum and glucocorticoid dependent kinase hSGK1 in lung fibrosis. Cell Physiol Biochem 42 2002; $12: 135-142$.

Waldegger S, Barth P, Raber G, Lang F: Cloning and characterization of a putative human serine/threonine protein kinase transcriptionally modified during anisotonic and isotonic alterations of cell volume. Proc Natl Acad Sci U S A 1997;94:4440-4445.

Boehmer C, Wilhelm V, Palmada M, Wallisch S, Henke G, Brinkmeier $\mathrm{H}$, Cohen P, Pieske B, Lang F: Serum and glucocorticoid inducible kinases in the regulation of the cardiac sodium channel SCN5A. Cardiovasc Res 2003;57:10791084.

33 Embark HM, Bohmer C, Vallon V, Luft F, Lang F: Regulation of KCNE1dependent $\mathrm{K}(+)$ current by the serum and glucocorticoid-inducible kinase (SGK) isoforms. Pflugers Arch 2003;445:601606 .

34 Busjahn A, Seebohm G, Luft FC, Lang F: Association of the Serum and Glucocorticoid Regulated Kinase (sgk1) Gene with QT Interval. Cell Physiol Biochem 2004; 14 :in press.

35 Staub O, Gautschi I, Ishikawa T, Breitschopf K, Ciechanover A, Schild L, Rotin D: Regulation of stability and function of the epithelial $\mathrm{Na}+$ channel $(\mathrm{ENaC})$ by ubiquitination. EMBO J 1997; 16:6325-6336.

36 Debonneville C, Flores SY, Kamynina E, Plant PJ, Tauxe C, Thomas MA, Munster C, Chraibi A, Pratt JH, Horisberger JD, Pearce D, Loffing J, Staub O: Phosphorylation of Nedd4-2 by Sgk1 regulates epithelial $\mathrm{Na}(+)$ channel cell surface expression. EMBO J 2001;20:7052-7059.

37 Snyder PM, Olson DR, Thomas BC: Serum and glucocorticoid-regulated kinase modulates Nedd4-2-mediated inhibition of the epithelial $\mathrm{Na}+$ channel. J Biol Chem 2002;277:5-8

38 Sanguinetti MC: Dysfunction of delayed rectifier potassium channels in an inherited cardiac arrhythmia. Ann N Y Acad Sci 1999;868:406-413.

39 Vincent GM: The molecular genetics of the long QT syndrome: genes causing fainting and sudden death. Annu Rev Med 1998;49:263-274.

Zhang Y, Wang H, Wang J, Han H, Nattel $\mathrm{S}$, Wang $\mathrm{Z}$ : Normal function of HERG $\mathrm{K}+$ channels expressed in HEK293 cells requires basal protein kinase $\mathrm{B}$ activity. FEBS Lett 2003;534:125-132.
Broer S, Broer A, Hamprecht B: Expression of $\mathrm{Na}+$-independent isoleucine transport activity from rat brain in Xenopus laevis oocytes. Biochim Biophys Acta 1994;1192:95-100.

Zerangue N, Arriza JL, Amara SG, Kavanaugh MP: Differential modulation of human glutamate transporter subtypes by arachidonic acid. J Biol Chem 1995;270:6433-6435.

$>43$ Huang FD, Chen J, Lin M, Keating MT, Sanguinetti MC: Long-QT syndrome-associated missense mutations in the pore helix of the HERG potassium channel. Circulation 2001;104:1071-1075.

Bell LM, Leong ML, Kim B, Wang E, Park J, Hemmings BA, Firestone GL: Hyperosmotic stress stimulates promoter activity and regulates cellular utilization of the serum- and glucocorticoid-inducible protein kinase (Sgk) by a p38 MAPKdependent pathway. J Biol Chem 2000;275:25262-25272.

45 Waldegger S, Gabrysch S, Barth P, Fillon S, Lang F: h-sgk serine-threonine protein kinase as transcriptional target of p38/MAP kinase pathway in HepG2 human hepatoma cells. Cell Physiol Biochem 2000;10:203-208.

Boehmer C, Henke G, Schniepp R, Palmada M, Rothstein JD, Broer S, Lang F: Regulation of the glutamate transporter EAAT1 by the ubiquitin ligase Nedd4-2 and the serum and glucocorticoid-inducible kinase isoforms SGK1/3 and protein kinase B. J Neurochem 2003;86:1181-1188.

Palmada M, Dieter M, Boehmer C, Waldegger S, Lang F: Serum and glucocorticoid inducible kinases functionally regulate $\mathrm{ClC}-2$ channels. Biochem Biophys Res Commun 2004;321:10011006.

Palmada M, Dieter M, Speil A, Bohmer C, Mack AF, Wagner HJ, Klingel K, Kandolf R, Murer H, Biber J, Closs EI, Lang F: Regulation of intestinal phosphate cotransporter $\mathrm{NaPi}$ IIb by ubiquitin ligase Nedd4-2 and by serum- and glucocorticoid-dependent kinase 1. Am J Physiol Gastrointest Liver Physiol 2004;287:G143-G150.

49 Boehmer C, Palmada M, Rajamanickam J, Schniepp R, Amara S, Lang F: Posttranslational regulation of EAAT2 function by co-expressed ubiquitin ligase Nedd4-2 is impacted by SGK kinases. J Neurochem 2006.

50 Lang F, Böhmer C, Palmada M, Seebohm G, Strutz-Seebohm N, Vallon V: Physiological and Pathophysiological Significance of the Serum- and Glucocorticoidinducible Kinase (SGK) Family of Protein Kinases. Physiol Rev 2006;11511178 . 